\title{
The experimental comparison of parameters signals of acoustic emission during destructive test on composites based on cement
}

\author{
Michaela Hoduláková ${ }^{1, *}$, Dalibor Kocáb ${ }^{1}$, Libor Topoláŕ ${ }^{1}$, and Barbara Kucharczyková1 \\ ${ }^{1}$ Brno University of Technology, Faculty of Civil Engineering, Veveři 331/95, Brno, Czech Republic
}

\begin{abstract}
The paper reports the analysis of acoustic emission signals captured during compressive strength tests of fine-grained cement-based composites of various composition. Acoustic emission monitoring belongs to a non-invasive and passive non-destructive testing technique. It is one of the most sensitive experimental techniques to monitor cracking of materials. While the acoustic emission phenomenon is directly associated with nucleation of cracks in materials based on cement, the measurement of these kinds of materials is readily applied to detect cracking activity. An understanding of microstructure-performance relationships is the key to true understanding of material behaviour.
\end{abstract}

\section{Introduction}

The concept of the water-cement ratio (w/c) is the basis of concrete technology because this ratio directly impacts the ultimate density, porosity, and mechanical properties of materials based on cement see Figure 1 [1].

The lower this ratio is, the stronger, more sustainable, less permeable and more durable the materials based on cement will be $[1,2]$. This is the reason, why superplasticizers, which allow the production of concrete (and other materials based on cement) with lower water content without compromising workability, are very popular and widely applied. In a short term, the early mechanical properties are linked primarily to the $\mathrm{w} / \mathrm{c}$ ratio, because the first hydrates that give the cement paste its strength are the ones that develop on the surface of the cement particles. In spite of the fact, that in materials with superplasticizers, there is not enough water for complete hydration, compressive strength continues to increase as the water-cement ratio (w/c) decreases. However, it was proved that it is not the hydration degree of cement particles that is determining compressive strength of the material, but their closeness in the cement paste [2].

This paper addresses to testing of several types of composites based on cement during the destructive test by one of the most interesting evaluation and diagnostic techniques for concrete structures, an acoustic emission (AE) technique (Figure 2). This non-destructive method is recently in great demand for maintenance purposes [3].

\footnotetext{
${ }^{*}$ Corresponding author: hodulakova.m@fce.vutbr.cz
} 
The AE method shows a significant potential to be applied for in-situ monitoring and evaluation of the current state of structures. It is applied during loading and it is often used to detect a failure at a very early stage, long before a structure completely fails [4]. This method is commonly used in bridge loading tests (e. g. the measurements of the bridge pillars) [5].

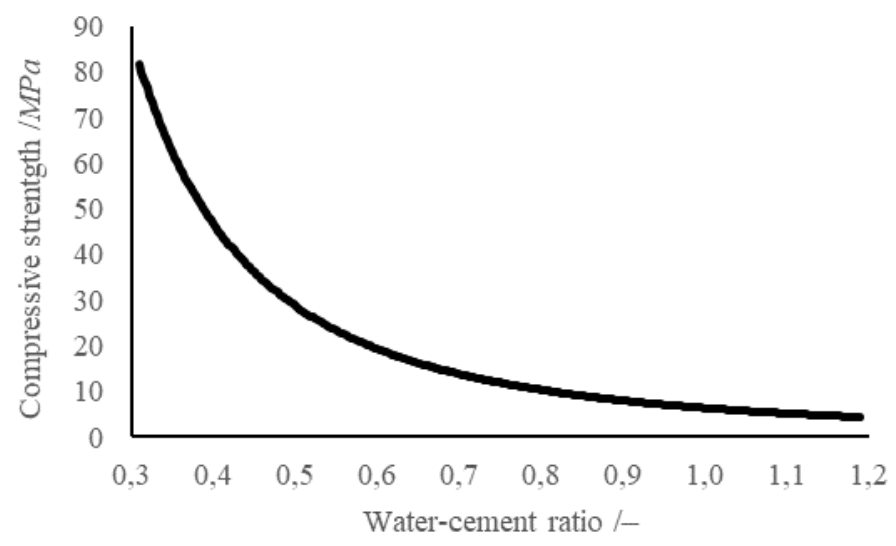

Fig. 1. The relationship between water-cement ratio and the compressive strength of concrete [6].

This method is based on detection of elastic waves by sensors directly attached (except for contactless sensors) to the surface of the specimen (Figure 3 and 4). These waves are defined as $\mathrm{AE}$ waves and generated due to the rapid release of stored strain energy from a localised source within a material. The sources of AE are deformation processes such as crack growth and plastic deformation. Propagations and patterns of cracks are mainly affected by loading types and conditions [7]. The initial cracking position may be dependent on the internal cracks and flaws during the loading, and the mechanical behaviour of specimens $[8,9]$.

After the detection of AE signals, as dynamic motions at the surface of a material, these signals are converted into the electric signal that is further amplified and filtered [4].

The measurement sensors are possible to calibrate after the sensors were stuck to the specimens (before loading tests) by means of Pen-test (Hsu-Nielsen source) [10].

The AE method only tracks the active actions (which take place during the measurement) in the material. The shape of the structure and the previous defects do not affect the measurement. The using of the AE method itself does not act upon the test specimen and the results [4].

There are some signal parameters which are useful to characterise the source of the AE event and are influenced by the crack mode. There is, for example, the amplitude, the duration, the rise time, AE energy and the cumulative number of AE counts.

Four parameters of each signal are recorded, calculated from the wave-forms (energy, duration, amplitude, the cumulative number of AE counts). These parameters are collected as the components of a vector associated with the signal they derive from.

The advantage of the AE technique, compare to other non-destructive testing method, is that AE method uses only few sensors in order to monitor the AE activity on entire structure. Another advantage is that the AE method does not require stopping during the loading, compared with the ultrasound method (which can be used for the measurement of defects too). In our experiment it is important not to stop the press during the compressive strength test because every stopping action could influence the value of the modulus of elasticity [4]. 


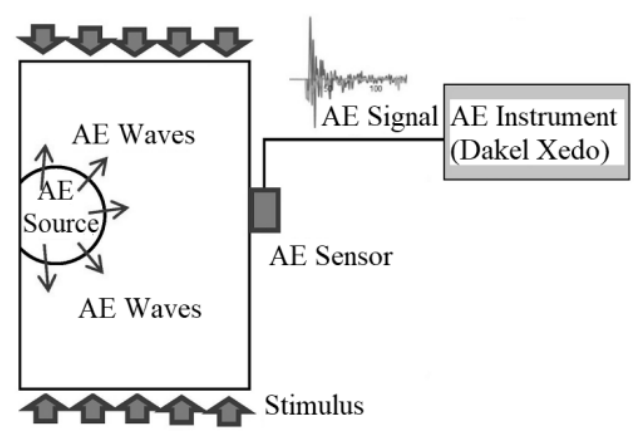

Fig. 2. Principle of acoustic emission measurement.

There are some limitations of the AE method too. In the case of a quick loading during compressive strength test, the AE method is less useful because there is a large number of signals that may not be recorded by the hardware of the AE measuring device.

Determining the behaviour of different kind of the material on the damage behaviour under compression loading using acoustic emission is quite common and is popular among other researchers $[11,12,13,14]$.

\section{Experimental setup}

The main aim of the performed experiments was to compare the acoustic responses during compressive strength test performed on the specimens at the age of three days. For this purpose, fine-grained cement composites were made, each with a different water-cement ratio and plasticizer content. The fresh composite formula is based on the ČSN EN 196-1 standard [15] for the testing of cement strength characteristics. Composites "M" were made of quartztite sand with the aggregate grain size distribution of 0-2 $\mathrm{mm}$, CEM I $42.5 \mathrm{R}$ Portland cement (Cement Plant Mokrá, Czech Republic) and water in ratio of 3:1:0.4 and 3:1:0.5 respectively (s:c:w). The composition of composites "MP" was modified by adding a Sika Viscocrete polycarboxylate-based super-plasticizer (Sika Group, Czech Republic) in amount of $1 \%$ by cement mass. The rest of components were the same. Table 1 shows the composition of composites. From each mixture, three test specimens with dimensions of $40 \times 40 \times 160 \mathrm{~mm}$ were manufactured and tested [16].

Table 1. Fresh mortar composition.

\begin{tabular}{|c|c|c|}
\hline \multirow{2}{*}{ Identification } & \multicolumn{2}{|c|}{ Components } \\
\cline { 2 - 3 } & s:c:w & $\begin{array}{c}\text { Superplasticizer by } \\
\text { cement mass [\%] }\end{array}$ \\
\hline 42_M_040 & $3: 1: 0.40$ & - \\
\hline 42_M_050 & $3: 1: 0.50$ & - \\
\hline 42_MP_040 & $3: 1: 0.40$ & 1 \\
\hline 42_MP_050 & $3: 1: 0.50$ & 1 \\
\hline
\end{tabular}

All specimens were coated with the PE foil during the hardening in laboratory conditions at a temperature of $(21 \pm 2)^{\circ} \mathrm{C}$ and relative humidity of $(60 \pm 10) \%$ until the time of testing. While testing compressive strength each specimen was placed in a testing FORM+TEST DELTA 6-300 hydraulic press with a range of $0-300 \mathrm{kN}$ as shown in Figure 3. Two acoustic emission sensors (type-IDK 09) with $35 d B$ preamplifiers were fixed to each specimen using beeswax. Acoustic emission signals were 
taken by measuring equipment DAKEL XEDO. Universal measurement and diagnostic system DAKEL-XEDO was developed by ZD Rpety-Dakel company. XEDO is a modular system. One communication card and up to 15 various input cards can be located in a metal box. Communication between cards within a box is performed by a hi-speed bus. It allows sampling of the signal from one sensor (speed up to $8 \mathrm{MSamples} / \mathrm{sec}$ ), enumerates standard acoustic emission parameters, process emission events parameters for possible emission source localization.

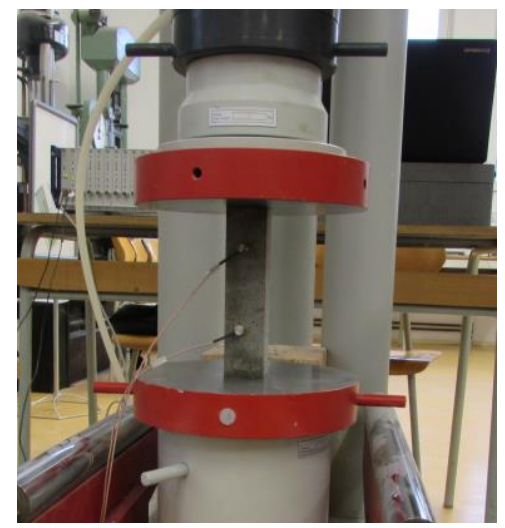

Fig. 3. Specimen location in the hydraulic press.

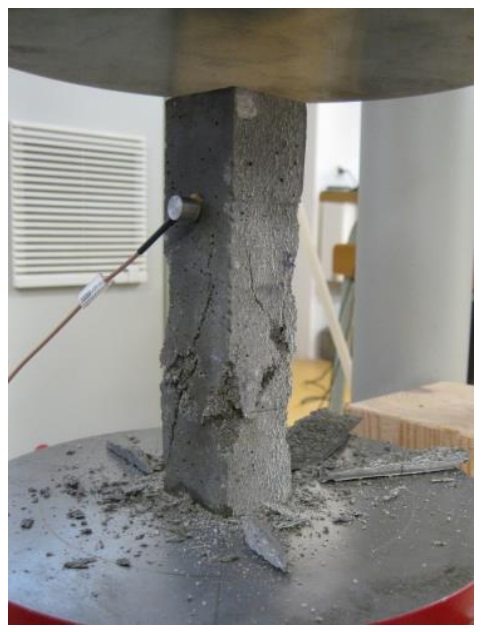

Fig. 4. The specimen 42_MP_050 after the test.

\section{Experimental results}

In order to describe acoustic emission signals formed during the compressive strength test in the prismatic beam, the attention was focused on the cumulative number of $\mathrm{AE}$ overshoots, duration, amplitude and energy of these signals. Different types of cracks generate different $\mathrm{AE}$ signals, these differences can be related to the properties of the material $[17,18]$. Duration of acoustic emission signal is the time difference between the first and last threshold crossings. The amplitude is the greatest measured voltage in a waveform. This is an important parameter in $\mathrm{AE}$ inspection because it determines detectability of the signal. The signals with amplitudes below the operator-defined 
minimum threshold are not recorded. The last monitored parameter acoustic emission energy is directly proportional to the area under the acoustic emission waveform.

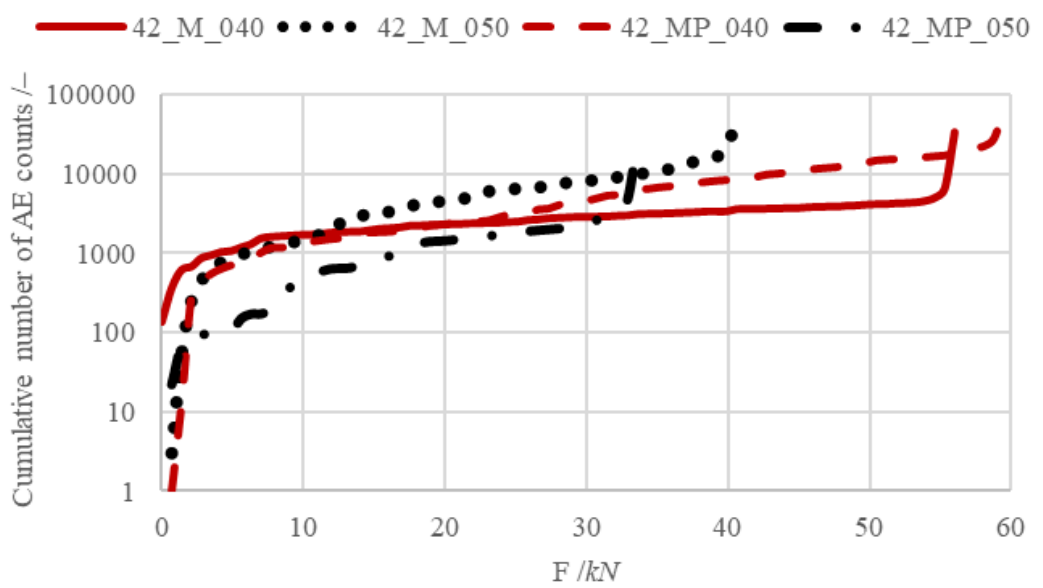

Fig. 5. The dependence of the cumulative number of AE overshoots on the loading force.

Figure 5 presents the loading process in relation with the $\mathrm{AE}$ events for all of the investigated composites. Based on the maximum value of a loading force, it can be estimated that the highest compressive strength was achieved in the case of the specimens made of mixture with the w/c of 0.40 with the addition of plasticizer. On the other hand, the mixture with the $\mathrm{w} / \mathrm{c}$ of 0.50 with plasticizer exhibited the lowest estimated compressive strength. In relation to the AE method, supposedly the least amount of cracks (within the interval of 10-30 kN) were formed in the specimens with the w/c of 0.50 with plasticizer. In contrast, the greatest amount of cracks was detected in the case of specimens with the w/c of 0.50 without plasticizer. The above described data are supposedly connected to the strength of the bond of the cementitious matrix of the material, where the mixtures with the lower $\mathrm{w} / \mathrm{c}$ have stronger bonds, more brittle at the same time. This effect is particularly evident for the mixture with the $\mathrm{w} / \mathrm{c}$ of 0.40 without a plasticizer, exhibiting a very sharp increase of $\mathrm{AE}$ counts at the moment of failure.

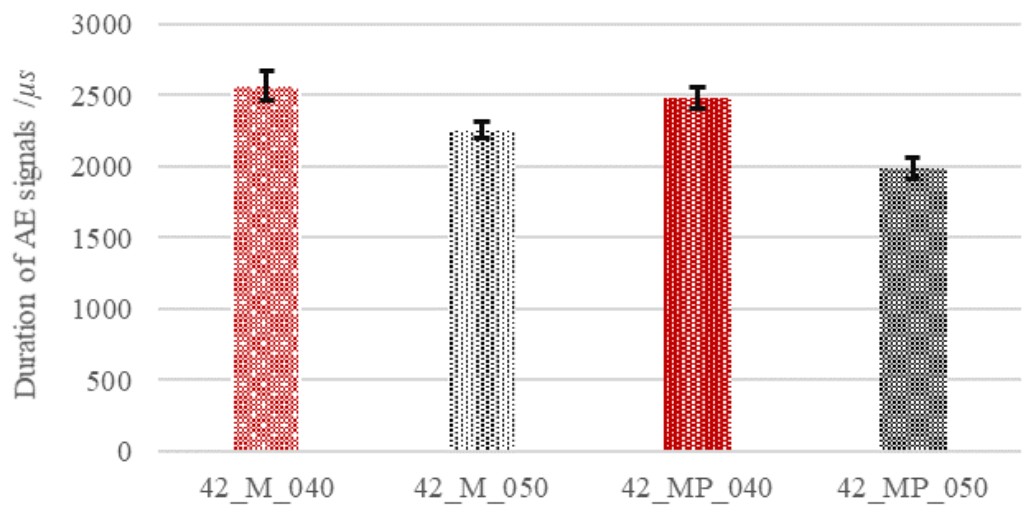

Fig. 6. The duration of AE signals for each specimen.

Figure 6 shows average duration of the AE signals for individual specimens during loading. It is evident that the specimens with a lower w/c show lower AE signal attenuation than the specimens with a higher water-cement ratio. This is probably due to the strength of 
the cementitious matrix and the fact that the specimens with the higher w/c exhibit the formation of air pores causing increased attenuation of the AE signal.

Figure 7 presents average amplitudes of the recorded AE signals. A higher amplitude value for specimens with the higher w/c indicates the formation of larger cracks during loading. This is caused again by the fact that the bond of the cementitious matrix of the specimens with the higher $\mathrm{w} / \mathrm{c}$ is more damage-prone.

The calculated values of the energy of the captured AE signals are shown in Figure 8. Obviously, the highest value in the case of specimens with the w/c of 0.40 and plasticizer was detected. This energy is predominantly related to the type of destruction of the specimen, where the specimen with the highest energy failed "explosively" into multiple pieces. The other specimens are more or less crumbled, see Figure 4.

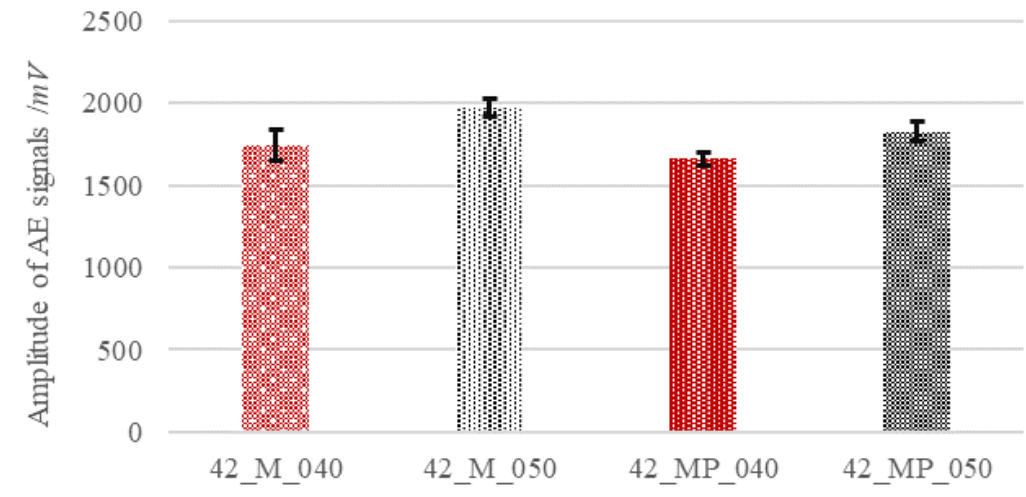

Fig. 7. The amplitude of AE signals for each specimen.

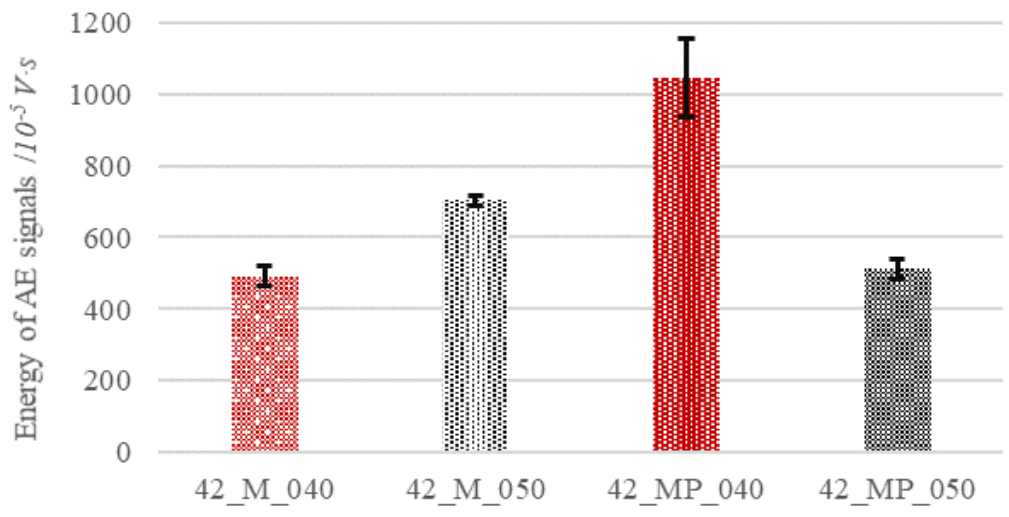

Fig. 8. The energy of AE signals for each specimen.

\section{Conclusion}

The experiments indicate that the acoustic emission method can significantly contribute to a more detailed insight into the behaviour of composite materials and structures during their lifespan. The acoustic emission method appears to be an interesting supplementary method for measuring the behaviour of composite constructions, structures and materials, during their production or under loading.

Based on the performed experiments, it can be stated that:

- a higher number of acoustic emission signal counts correspond to the formation of a higher number of new microcracks, 
- a higher amplitude value of the acoustic emission signals or released energy of acoustic emission signals correspond to more significant structural changes, which occur in the structure of the material.

Larger structural changes during the test were performed in specimens with a higher water-cement ratio. The plasticizer reduced structural damages.

This research was supported by the Czech Science Foundation under the project no. 17-14302S

"Experimental analysis of the early-age volume changes in cement-based composites".

\section{References}

1. H. W. Reinhardt, C. U. Grosse, Advanced testing of cement based materials during setting and hardening (RILEM Publications S.A.R.L., 2005)

2. P.C. Aitcin, R. J. Flatt, Science and technology of concrete admixtures (Woodhead Publishing, 2015)

3. M. Ohtsu, T. Suzuki, Journal of Acoustic Emission, 22 (2005)

4. Ch. U. Grosse, M. Ohtsu, Acoustic Emission Testing (Heidelberg: Springer, 2008)

5. P. Olaszek, J. R. Casas, G. Świt, On-site assessment of bridges supported by acoustic emission, in: Proceedings of the Institution of Civil Engineers-Bridge Engineering, 169(2), 81-92 Thomas Telford Ltd (2015)

6. Journal of the Network of African Countries on Local Building Materials and Technologies, 3(2) (HABITAT, 1994, 42 p.): Technology Profile No. 1 - Fibreconcrete Roofing**. New Zealand Digital Library [online]. University of Waikato [cit. 2018-01-17]. Available on: http://www.nzdl.org/gsdlmod?e=d-00000-00---off-0cdl-00-0----0-10-0---0---0direct-10---4-------0-11--11-en-50---20-about---00-0-1-00-0-0-111-0utfZz-8-00\& $\mathrm{a}=\mathrm{d} \& \mathrm{cl}=\mathrm{CL} 1.137 \& \mathrm{~d}=\mathrm{HASH} 01 \mathrm{f1} 1813030 \mathrm{e} 134 \mathrm{a} 3 \mathrm{~d} 7292 \mathrm{eca} .5$

7. E. K. Tschegg, A. Schneemayer, I. Merta, K. A. Rieder, Cement and Concrete Composites, 62 (2015)

8. M. A. A. Aldahdooh, N. M. Bunnori, Construction and Building Materials, 45 (2013)

9. R. V. Sagar, B. R. Prasad, Nondestructive Testing and Evaluation, 27 (2012)

10. Z. Cáb, Using of non-destructive test of accoustic emission for prolonging the operation life of composite pressure cylinders. TRANSACTIONS of the VŠBTechnical University of Ostrava, Safety Engineering Series, 11(2), 51-55 (2016)

11. N. Kosmann, J. M. Karsten, M. Schuett, K. Schulte, B. Fiedler, Determining the effect of voids in GFRP on the damage behaviour under compression loading using acoustic emission. Composites Part B: Engineering, 70, 184-188 (2015)

12. L. Topoláŕ, L. Pazdera, P. Cikrle, Acoustic emission monitoring during static modulus elasticity test of concrete specimen. In Applied Mechanics and Materials (Vol. 486, pp. 267-272). Trans Tech Publications (2014)

13. E. D. Pasiou, D. Triantis, Correlation between the electric and acoustic signals emitted during compression of brittle materials. Frattura ed Integrità Strutturale, (40), 41 (2017)

14. Q. Meng, M. Zhang, L. Han, H. Pu, T. Nie, Effects of acoustic emission and energy evolution of rock specimens under the uniaxial cyclic loading and unloading compression. Rock Mechanics and Rock Engineering, 49(10), 3873-3886, (2016)

15. EN 196 - 1: Methods of testing cement (2005)

16. L. Topolár̆, L. Pazdera, B. Kucharczyková, J. Smutný, K. Mikulášek, Applied Sciences, 7 (2017)

17. K. Ohno, M. Ohtsu, Construction and Building Materials, 24 (2010)

18. Z. Li, Y. Xi, Non-Destructive Testing in Civil Engineering (1995) 